\begin{tabular}{|l|l|l|l|l|}
\hline Cuadernos I. Geográfica & $22-23$ & pp. 97-114 & Logroño & 1996-97 \\
\hline
\end{tabular}

\title{
CARACTERIZACIÓN DE LA PLUVIOSIDAD DE BAHÍA CUMBERLAND (ISLA DE ROBINSON CRUSOE, CHILE)
}

\author{
M. ${ }^{\text {a V. MARZOL }}$ \\ P. CERECEDA ${ }^{2}$ \\ R. SCHEMENAUER ${ }^{3}$ \\ C. CASTRO ${ }^{2}$
}

\begin{abstract}
RESUMEN: En Babía Cumberland, isla Robinson Crusoe, los riesgos de aluvión y los fuertes procesos erosivos son muy altos, de abí el interés de conocer el comportamiento de la lluvia. La irregularidad e intensidad son sus rasgos más relevantes. Las precipitaciones se concentran entre abril y septiembre, siendo el total anual de $1023,7 \mathrm{~mm}$ (1960-1994). La intensidad en 12 boras más frecuente (el 58.3\%) oscila entre los 1.0 y $9.9 \mathrm{~mm}$. Las mayores intensidades registradas ban sido de $290.3 \mathrm{~mm}$ en 24 boras y de $265.0 \mathrm{~mm}$ en 12 boras. En siete ocasiones se sobrepasó los $100 \mathrm{~mm}$ en un día, ocurriendo dos de ellas en el mismo año.

ABSTRACT: In Babia Cumberland, in Robinson Crusoe Island, is important to study the precipitation regime because the risks of flood and of severe erosion are high. The two most relevant characteristics are the intensity and irregularity of the precipitation. The average annual precipitation (1960-1994) was $1023.7 \mathrm{~mm}$, with seventy six percent falling between $290.3 \mathrm{~mm}$ in 24 bours and $265.0 \mathrm{~mm}$ in 12 bours. On seven occasions it rained more than $100 \mathrm{~mm}$ in a day, including twice in one year.
\end{abstract}

Palabras clave: Precipitación, intensidad, aluviones, Robinson Crusoe, Chile. Key words: precipitation, intensity, risks of flood, Robinson Crusoe, Chile.

1. Departamento de Geografía. Universidad de La Laguna. Canarias. España.

2. Instituto de Geografia. Pontificia Universidad Católica de Chile. Santiago de Chile.

3. Atmospheric Environment Service. 4905 Dufferin street. Downsview. Ontario. Canadá. 


\section{Introducción}

La isla de Robinson Crusoe ( $\left.33^{\circ} 37^{\prime} \mathrm{S}, 78^{\circ} 53^{\prime} \mathrm{W}\right)$, con una extensión superficial de $47,7 \mathrm{~km}^{2}$, se encuentra en el Pacífico Sur, a $670 \mathrm{~km}$ de distancia de la costa sudamericana. Forma parte del archipiélago de Juan Fernández, que fue declarado Parque Nacional por el Gobierno chileno en 1935 y Reserva de la Biosfera en 1977 por la UNESCO, debido a su interés biogeográfico y a la necesidad de su preservación.

La única población existente en la isla, el poblado de San Juan Bautista, se localiza en Bahía Cumberland, con cerca de 600 habitantes, dedicados en su mayoría a la captura de la langosta. Es una bahía abierta a los vientos del Noreste, en la que desembocan 6 quebradas principales que drenan una superficie de $8.5 \mathrm{~km}^{2}$ y que están delimitadas por las elevaciones montañosos más importantes de la isla: El Yunque (915 m.s.n.m.), el Cerro Central (800 metros) y el Cordón Atravesado (550 metros). La abundancia de quebradas, algunas de ellas con valles muy profundos, ocasiona que en los mayores episodios lluviosos se concentre un gran volumen de agua discurriendo por todas ellas y transportando gran cantidad de materiales sólidos procedentes de las laderas, que en algunos momentos han llegado a producir aluvionamientos sobre el núcleo poblacional (Fig. 1).
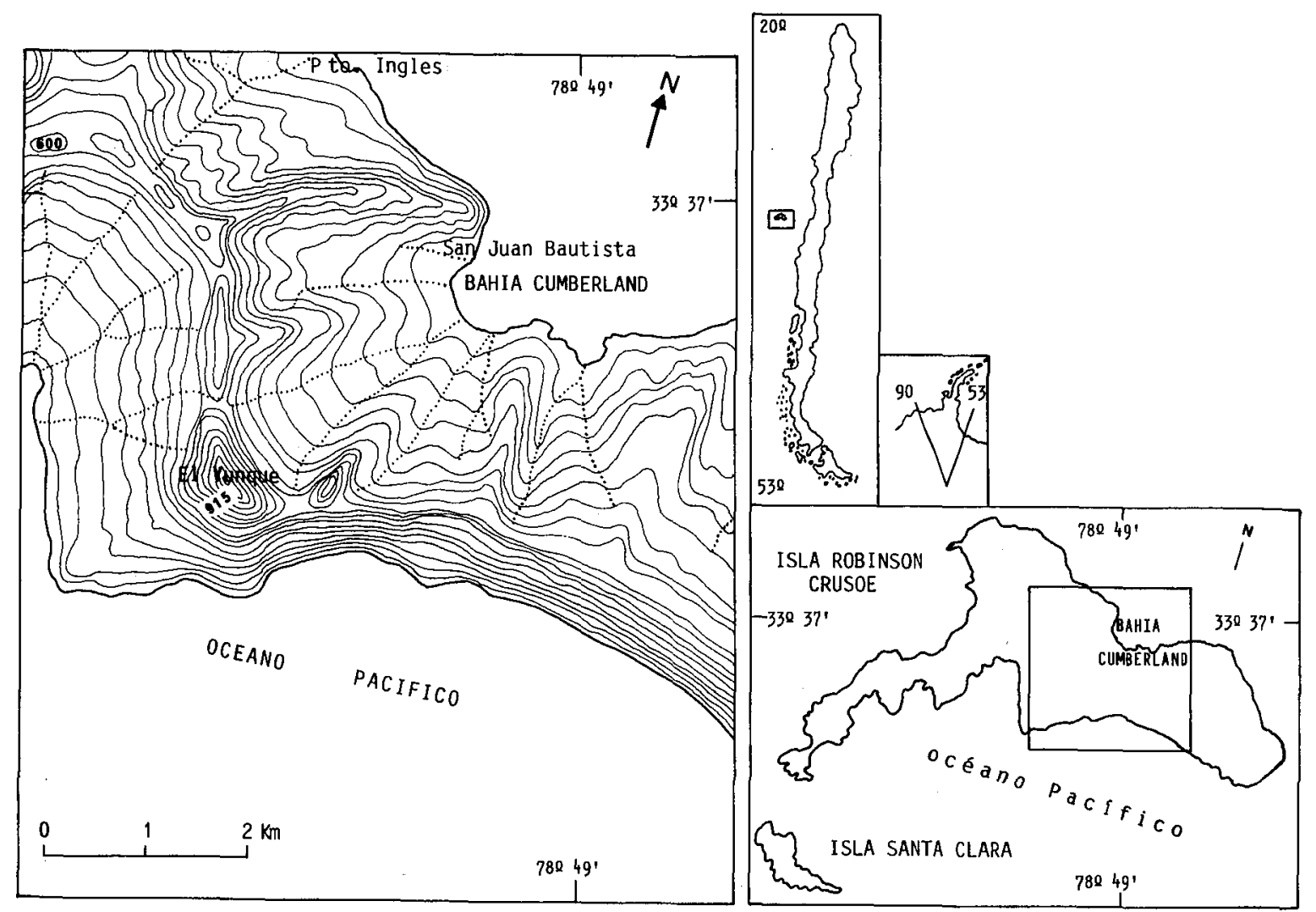

Figura. 1. Localización de Babía Cumberland en la isla Robinson Crusoe $\left(33^{\circ} 37^{\prime} s ; 78^{\circ} 53^{\prime} \mathrm{W}\right.$, Chile. 
El clima de Bahía Cumberland, según la clasificación de Köppen es Csb, templado-cálido y húmedo con verano corto y seco. El hiterógrafo muestra la condición cálida-húmeda y el climógrafo indica esta cualidad térmica y una precipitación diferenciada estacionalmente, al ocupar los cuadrantes cálido-seco y cálido lluvioso (Figs. 2a,b).

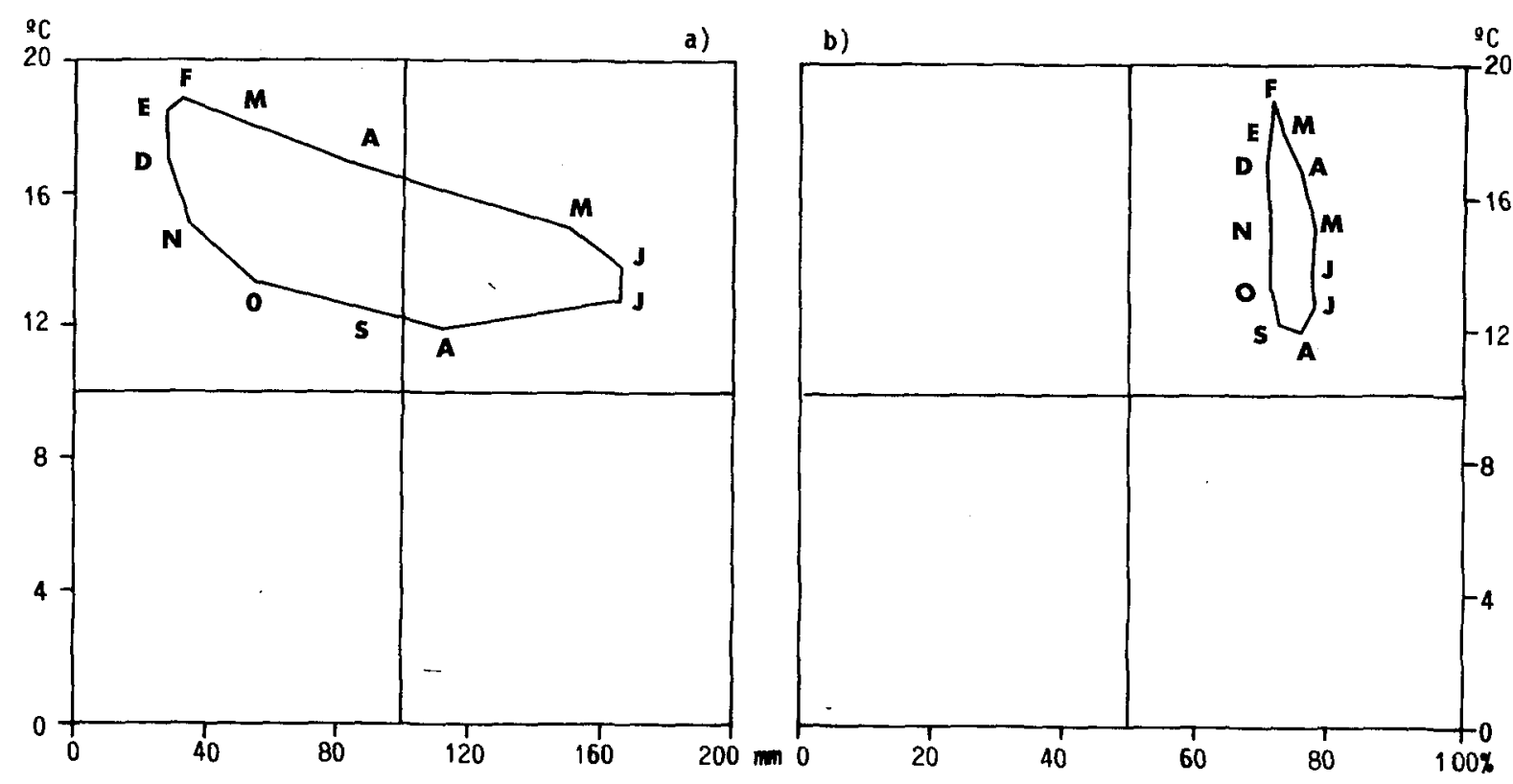

Figura 2: El climógrafo (a) y el biterógrafo (b) de Babía Cumberland (1961-1994).

Es interesante consignar que, estando Robinson Crusoe a la misma latitud de Valparaíso, los montos de precipitación son tres veces más elevados en la primera $^{1}$. La explicación puede buscarse en el hecho de que el archipiélago de Juan Fernández se encuentra al Oeste y fuera de la influencia de la corriente de Humboldt, cuyas aguas frías contribuyen a la estabilización de las masas de aire superficiales en esta latitud, dificultando notablemente la generación de las lluvias. Aunque éstas son de origen ciclónico porque la isla se encuentra en la ruta de las depresiones frontales, el efecto orográfico va a intensificar la cantidad e intensidad de esas precipitaciones (MARZOL,1988a).

En general, el comportamiento de la precipitación en las islas es muy particular. La altitud, así como la orientación y la exposición de las laderas, son el factor geográfico condicionante primordial de importantes diferencias espaciales. Por este motivo las características climáticas de Bahía Cumberland no pueden hacerse extensivas a todo el territorio insular, en el que se pueden distinguir dos paisajes geográficos bien diferenciados y vertebrados en torno al cordón cen-

1. S. CAVIEDES, en 1971, establece una relación de 6 a 1 entre ambas localidades. 
tral. El sector occidental, de topografía plana y ondulada, presenta rasgos semiáridos (CERECEDA et al., 1994) con vegetación herbácea de escasa cobertura y con manifestaciones de intensos procesos erosivos (CASTRO et al., 1995). El sector oriental, en cambio, posee una fisonomía montañosa y en sus partes altas domina el bosque fernandeziano (Nortbomyrcia Fernandeziana, Fajara mayul, Drimys confertifolia, Cuminia Fernandezia, Cuminia eriantba, etc.), compuesto por gran cantidad de especies endémicas, mientras que las áreas más bajas están ocupadas por un matorral y pastizal degradados.

Este bosque se sustenta no sólo por la lluvia sino que también intercepta y colecta la niebla, que es muy frecuente a partir de los 400 metros (CERECEDA et al., 1994; ZUNINO, 1993).

Conocer las características de las lluvias en Bahía Cumberland, donde se halla la única estación meteorológica de la isla, es importante debido a que los ecosistemas son muy frágiles y se encuentran amenazados por la erosión e invasión de especies foráneas; asimismo, el poblado de San Juan Bautista ha sufrido severos aluviones a lo largo de su historia. Mientras que en el primer caso la información obtenida sólo puede servir de referencia, en el segundo es de gran utilidad ya que el poblado se enclava en dicha bahía.

\section{Objetivo, materiales y método}

El objetivo del trabajo es caracterizar climáticamente la Bahía de Cumberland, haciendo hincapié en el régimen pluviométrico ya que éste tiene claras implicaciones geomorfológicas, biogeográficas y sociales. Las conclusiones obtenidas podrán servir para prever los efectos secundarios que acarrea la combinación de un régimen lluvioso espasmódico y una cubierta vegetal muy degradada, con predominio de gran cantidad de materiales sueltos dispuestos a ser arrastrados. Como ya se ha dicho, los resultados no son generalizables a toda la isla.

El estudio se ha basado en los datos proporcionados por la estación meteorológica de Juan Fernández. Fue creada por la Dirección Meteorológica de Chile en el año 1902 y situada a 6 m.s.n.m. con las coordenadas $33^{\circ} 37^{\prime} \mathrm{S} ; 7^{\circ} 50^{\prime} \mathrm{W}$. En el mes de junio de 1978 sufrió un traslado de 400 metros de distancia, dentro de la misma bahía, siendo su localización actual en el Fuerte de Santa Bárbara, a 30 m.s.n.m. ( $\left.33^{\circ} 37^{\prime} \mathrm{S} ; 7^{\circ} 49^{\prime} \mathrm{W}\right)$. Posee una serie muy larga y fiable.

La información meteorológica recopilada no es homogénea debido a los sucesivos cambios en el formato de los registros y a la propia necesidad de la investigación, dirigida sobre todo al estudio de las precipitaciones. Para caracterizar el régimen térmico se han analizado las temperaturas extremas desde 1902 a 1994. En el régimen higrométrico se han obtenido los valores medios mensuales a tres horas diferentes del día (8, 14 y 20 horas) desde 1960 hasta 1979 , además de los años 1985, 1988, 1990 y 1991. La presión media utilizada es la corregida al nivel del mar entre 1968 y 1991, faltando los años 1983, 1984, 1986 
y 1987. En el caso del régimen pluviométrico, debido a su mayor interés, se ha trabajado con la serie de totales mensuales desde 1902 hasta la actualidad, utilizando el mismo período para la intensidad máxima anual registrada en 24 horas. Sin embargo, ante la necesidad de estudiar intensidades en tiempos inferiores se ha recogido la lluvia diaria, en períodos de 12 horas, desde 1960 hasta 1994 . No ha sido posible retrotraerse a esa fecha por no disponer de ese tipo de información en la Dirección Meteorológica de Chile.

El estudio climático elaborado se ha basado exclusivamente en el método analítico y tan sólo se ha analizado la dinámica de las masas de aire para caracterizar las situaciones atmosféricas que han causado las precipitaciones más intensas conocidas en Bahía Cumberland. Las herramientas estadísticas utilizadas son las propias de esta metodología y con ellas se han obtenido los valores extremos y medios de todos los elementos climáticos registrados en Bahía Cumberland. En el caso de las precipitaciones se han hallado los índices de tendencia central y dispersa más comunes, la desviación estándar de los totales anuales, los quintiles, las frecuencias y la probabilidad; también se ha aplicado la fórmula de los períodos de retorno de Gumbel a la máxima precipitación en 24 y 12 horas para obtener una estimación de los máximos eventos lluviosos.

\section{Resultados}

a) El régimen termohigrométrico, la presión atmosférica y los vientos.

Las temperaturas de Bahía Cumberland son templadas durante todo el año, con una media anual de $15.3^{\circ} \mathrm{C}$ (O.M.M.1964). La máxima absoluta, desde 1902 a 1994 , es de $28.9^{\circ} \mathrm{C}$ (registrada en 1982) y la mínima absoluta de $3.0^{\circ} \mathrm{C}$, en el año 1965; hay pues una oscilación extrema de $25.9^{\circ} \mathrm{C}$, aunque lo normal es que la oscilación de cada año esté en torno a los $20.0^{\circ} \mathrm{C}$.

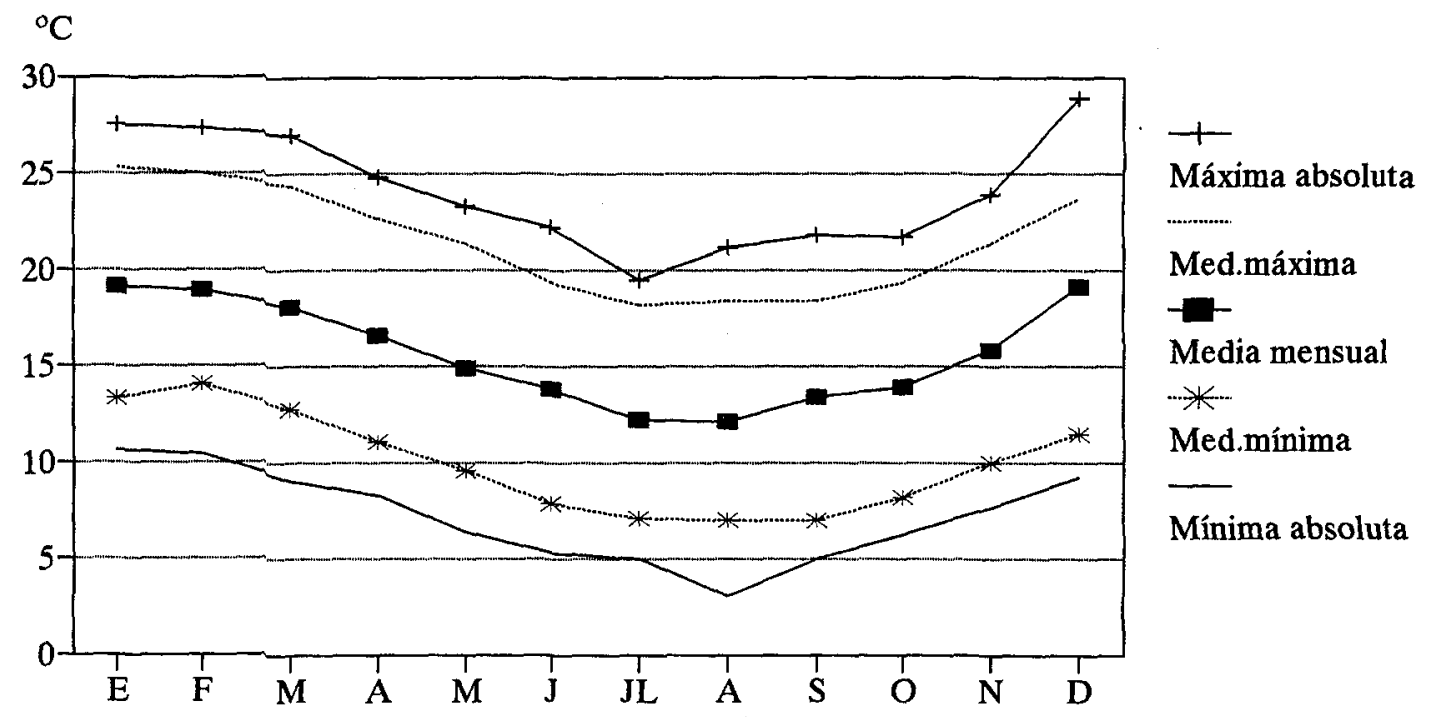

Figura 3: El régimen térmico de Babía Cumberland (1902-1994). 
En el régimen térmico se puede apreciar que tanto la oscilación anual como la diaria son moderadas (Fig. 3). La diferencia entre la temperatura del mes más cálido $\left(19.1^{\circ} \mathrm{C}\right)$ y la del mes más frío $\left(12.1^{\circ} \mathrm{C}\right)$ es de $7.0^{\circ} \mathrm{C}$; esta oscilación es menor aún si se compara la temperatura media de las 7 y las 13 horas, que es de $2.6^{\circ} \mathrm{C}$, siendo algo más alta en verano $\left(3.0^{\circ} \mathrm{C}\right)$.

La humedad relativa del aire es elevada y varía muy poco a lo largo del año, con el $74 \%$ de media anual. Aunque los meses más secos son los del verano en éstos nunca es inferior al 71\%, y en el invierno se mantiene el 78\%. Al analizar la variación diaria de este elemento climático, se observa que la humedad es más alta en las primeras horas del día, tanto en verano como en invierno: el $75 \%$ desde noviembre a enero y el $81 \%$ de mayo a julio. Al mediodía disminuye notablemente, sobre todo en verano que llega a ser del $67 \%$, y vuelve a subir en las primeras horas del anochecer. En la Figura 4 se ve que los valores de las 8 y 20 horas tienen mayor influencia en la media mensual que el de las 14 horas.

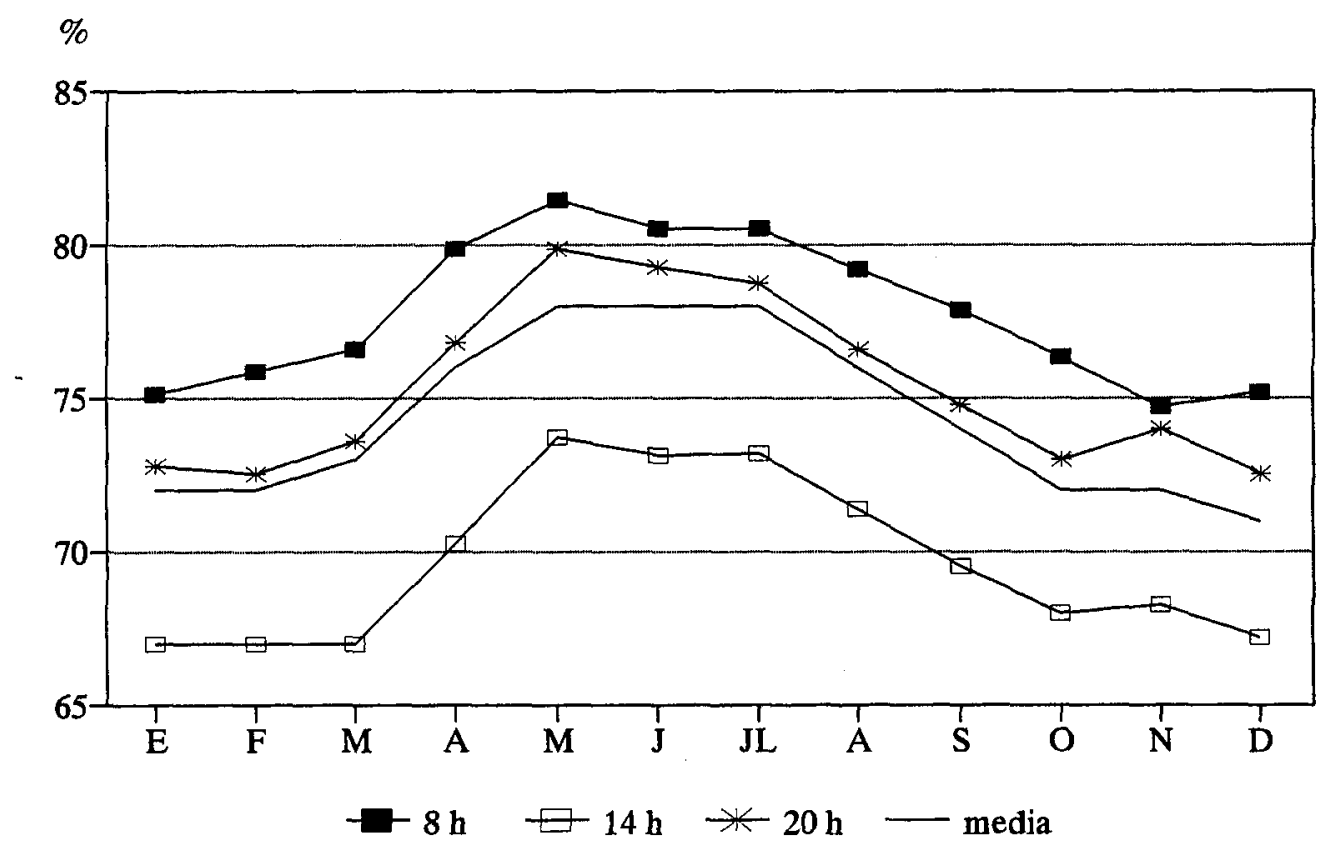

Figura 4. El régimen higrométrico de Babía Cumberland (1960-1979, 1985, 1988, 1990-1991).

En el Pacífico suroriental, la banda de altas presiones subtropicales aparece dividida en tres grandes células (PEÑA et al, 1976). Una de ellas, la más oriental tiene su núcleo centrado entre $\operatorname{los} 27^{\circ}$ y $38^{\circ} \mathrm{S}-80^{\circ}$ y $100^{\circ} \mathrm{W}$, al Oeste del archipiélago de Juan Fernández. Esto explica que la presión media anual sea elevada, de $1020 \mathrm{hPa}$ al nivel del mar. Mayo, con una media de $1018 \mathrm{hPa}$, es el mes con la presión más baja mientras que el valor más elevado se registra desde agosto hasta finales de octubre, con $1022 \mathrm{hPa}$.

Al relacionar la presión media mensual con la pluviosidad, se observa que el descenso de la primera en el mes de mayo coincide con el aumento de las llu- 
vias y, al contrario, cuando la presión alcanza su punto más alto es cuando comienza el declive de las segundas.

En verano, debido a que el anticiclón se desplaza hacia latitudes superiores, los vientos dominantes en Juan Fernández son los alisios del Sur; en cambio, durante el invierno la retirada del centro anticiclónico hacia el Norte favorece el paso de las perturbaciones oceánicas predominando, en este caso, los vientos de componente oeste.

\section{b) El régimen pluviométrico de Bahía Cumberland}

La pluviosidad de Bahía Cumberland es considerable, con una media anual de $982.8 \mathrm{~mm}$ (1902-1994) y de $1023.7 \mathrm{~mm}$ (1960-1994). Las lluvias se concentran en el otoño y el invierno ya que algo más de las tres cuartas partes del monto total caen entre abril y septiembre.

\section{1) La pluviosidad media anual y mensual.}

Uno de los rasgos principales de la lluvia de este lugar es su notable irregularidad, tanto anual como mensual. Ha habido años en los que no se han alcanzado los $600 \mathrm{~mm}$ (por ejemplo 1936 y 1937) frente a otros en los que se han superado los 1600 mm (1922, 1972 y 1980), siendo la desviación estándar de los totales de 73 años ${ }^{2}$ de $228,4 \mathrm{~mm}$. Según los quintiles, en Bahía Cumberland se considera que un año es muy seco cuando llueve menos de $831 \mathrm{~mm}$, seco cuando el total está comprendido entre 831 y $938 \mathrm{~mm}$, es normal si la lluvia anual oscila entre 938 y 1026 mm, lluvioso entre 1026 y 1155 mm, y muy lluvioso si supera este último umbral (Fig. 5).

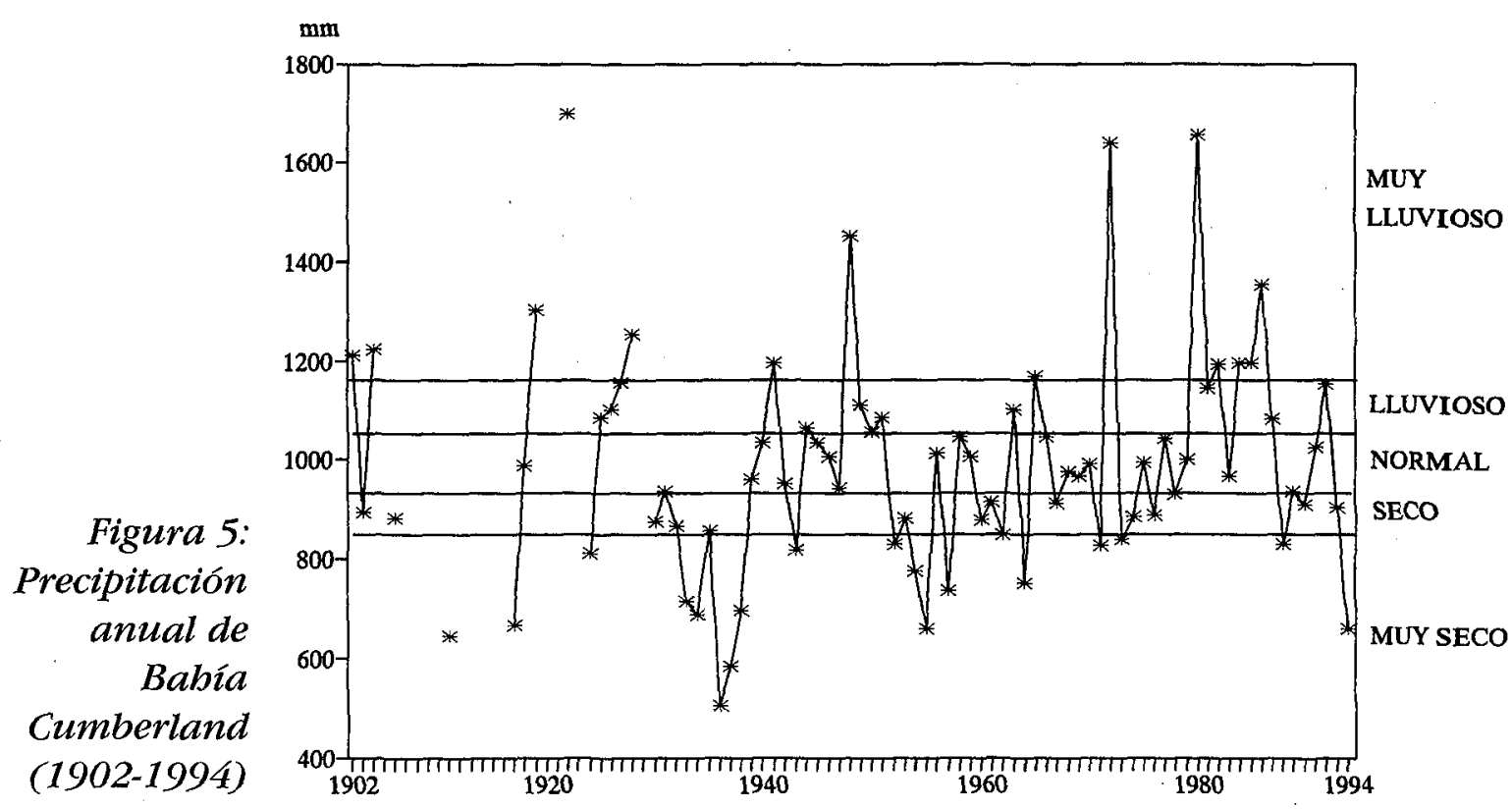

2. Sólo se han utilizado los años que disponen información de los 12 meses, un total de 73 en la serie 1902-1994. 
La lluvia anual más frecuente (la moda) se halla entre los intervalos de 900.0 y $1100.0 \mathrm{~mm}$ (de un total de 73 años, se han registrado estas cantidades en 30 ocasiones, el 41\%); el valor de la mediana es de $972.0 \mathrm{~mm}$ y la media de $982.8 \mathrm{~mm}$.

CUADRO I
FRECUENCIA DE LA PRECIPITACIÓN
ANUAL EN BAHÍA CUMBERIAND (1902-1994)
\begin{tabular}{|c|c|}
\hline \multicolumn{1}{|c|}{ Intervalos } & Número \\
mm & de años \\
\hline De 500 a 600 & 2 \\
600 a 700 & 5 \\
700 a 800 & 4 \\
800 a 900 & 13 \\
900 a 1.000 & 15 \\
1.000 a 1.100 & 15 \\
1.100 a 1.200 & 10 \\
1.200 a 1.300 & 3 \\
1.300 a 1.400 & 2 \\
1.400 a 1.500 & 1 \\
1.500 a 1.600 & 0 \\
1.600 a 1.700 & 3 \\
TOTAL & 73 \\
\hline
\end{tabular}

En el cuadro II, donde figuran las precipitaciones totales anuales ordenadas en magnitud creciente, se observa que existe una probabilidad del $50 \%$ de que las lluvias anuales en Bahía Cumberland sean inferiores a $976.6 \mathrm{~mm}$; un $25 \%$ de que sean inferiores a $859.0 \mathrm{~mm}$; y un $75 \%$ de que lo sean a $1102.8 \mathrm{~mm}$.

La precipitación diaria acumulada ${ }^{3}$ indica que lo normal es que a fines de junio se haya alcanzado la mitad de toda la lluvia anual, en la primera decena de mayo el $25 \%$ del total y el 15 de agosto las $3 / 4$ partes de la misma. Esto quiere decir que en tres meses y cinco días, desde el 10 de mayo hasta el 15 de agosto, cae el 50\% de la lluvia anual y el otro $50 \%$ lo hace en ocho meses y veinticinco días.

El 76\% de la precipitación media anual, de $1023.7 \mathrm{~mm}^{4}$, cae entre abril y septiembre, meses en los que llueve más de $80.0 \mathrm{~mm}$ cada uno, siendo los más lluviosos junio y julio con una media de $169.7 \mathrm{~mm}$ y $166.7 \mathrm{~mm}$ respectivamente. Por el contrario, el período más seco comprende desde noviembre hasta finales de febrero, con sólo el $12.5 \%$ del total anual; en todos estos meses llueve menos de $35.0 \mathrm{~mm}$ y sólo tienen 9 ó 10 días de lluvia cada uno frente a los 20 días de los meses invernales (ver Anexo D).

3. Realizada por la Dirección Meteorológica de Chile sobre la serie 1961-1990.

4 . Se utiliza la serie 1960-1994 para así poder establecer la relación de la cantidad de lluvia con el número de días de lluvia y con la intensidad diaria y horaria. 
CARACTERIZACIÓN DE LA PLUVIOSIDAD DE BAHÍA CUMBERLAND (ISLA DE ROBINSON CRUSOE) CFILE

CUADRO II

PRECIPITACIONES ANUALES EN ORDEN CRECIENTE Y PROBABILIDAD DE QUE SE REGISTRE EN UN AÑ̃ PRECIPITACIONES MAS BAJAS EN BAHÍA CUMBERLAND (1902-1994)

\begin{tabular}{|c|l|l|l|l|l|l|l|l|}
\hline $\mathbf{N 1}$ & $\mathbf{m m}$ & $\mathbf{P}$ & $\mathbf{N 1}$ & $\mathbf{m m}$ & $\mathbf{P}$ & $\mathbf{N 1}$ & $\mathbf{m m}$ & $\mathbf{P}$ \\
\hline 1 & 506.2 & 0.01 & 25 & 904.8 & 0.34 & 49 & 1048.0 & 0.66 \\
2 & 584.2 & 0.02 & 26 & 910.0 & 0.35 & 50 & 1056.0 & 0.67 \\
3 & 659.3 & 0.04 & 27 & 911.7 & 0.36 & 51 & 1064.0 & 0.69 \\
4 & 660.0 & 0.05 & 28 & 915.3 & 0.38 & 52 & 1082.1 & 0.70 \\
5 & 667.5 & 0.07 & 29 & 929.6 & 0.39 & 53 & 1085.0 & 0.71 \\
6 & 687.0 & 0.08 & 30 & 938.0 & 0.40 & 54 & 1087.0 & 0.73 \\
7 & 697.0 & 0.09 & 31 & 938.6 & 0.41 & 55 & 1100.5 & 0.74 \\
8 & 715.0 & 0.11 & 32 & 944.2 & 0.43 & 56 & 1102.8 & 0.75 \\
9 & 735.0 & 0.12 & 33 & 951.0 & 0.44 & 57 & 1143.6 & 0.77 \\
10 & 752.5 & 0.13 & 34 & 963.0 & 0.46 & 58 & 1152.3 & 0.78 \\
11 & 777.3 & 0.15 & 35 & 966.8 & 0.47 & 59 & 1155.5 & 0.80 \\
12 & 812.6 & 0.16 & 36 & 967.4 & 0.49 & 60 & 1169.9 & 0.81 \\
13 & 818.0 & 0.18 & 37 & 976.6 & 0.50 & 61 & 1194.2 & 0.82 \\
14 & 827.8 & 0.19 & 38 & 992.7 & 0.51 & 62 & 1195.2 & 0.83 \\
15 & 831.0 & 0.20 & 39 & 996.1 & 0.52 & 63 & 1196.0 & 0.85 \\
16 & 831.9 & 0.21 & 40 & 1001.5 & 0.54 & 64 & 1197.1 & 0.86 \\
17 & 840.4 & 0.23 & 41 & 1005.9 & 0.55 & 65 & 1212.1 & 0.88 \\
18 & 850.0 & 0.24 & 42 & 1008.0 & 0.57 & 66 & 1224.4 & 0.89 \\
19 & 859.0 & 0.25 & 43 & 1012.0 & 0.58 & 67 & 1253.7 & 0.90 \\
20 & 866.0 & 0.27 & 44 & 1026.2 & 0.59 & 68 & 1301.0 & 0.92 \\
21 & 878.2 & 0.28 & 45 & 1034.0 & 0.60 & 69 & 1353.3 & 0.93 \\
22 & 881.2 & 0.30 & 46 & 1034.0 & 0.62 & 70 & 1450.3 & 0.94 \\
23 & 886.6 & 0.31 & 47 & 1042.0 & 0.63 & 71 & 1639.3 & 0.96 \\
24 & 886.9 & 0.32 & 48 & 1047.5 & 0.65 & 72 & 1659.9 & 0.97 \\
& & & & & & 73 & 1697.7 & 0.99 \\
\hline
\end{tabular}

N1: número de orden.

mm: precipitación total anual

$\mathrm{P}$ : probabilidad $(\mathrm{P}=\mathrm{N} / \mathrm{n}+1$, siendo $\mathrm{n}$ : número de términos).

Consideramos que en esta ocasión no es correcto realizar la distribución estacional de la lluvia en sensu estricto porque el mes de noviembre reúne las mismas condiciones que los meses del verano, en los que la lluvia supone alrededor del 3\% del total anual y el número de días con lluvia está entre el 5\% y el 6\% (Fig.6). Por el contrario, el mes de mayo, sin duda, forma parte del grupo invernal con los de junio, julio y agosto porque todos ellos recogen similar volumen de agua en el mismo número de días de lluvia (15\% y 10\% respectivamente). Finalmente, marzo, abril, septiembre y octubre son meses de transición; en cada uno de ellos cae entre el 5\% y el 9\% de las precipitaciones del año en el $8 \%$ de los días lluviosos. 


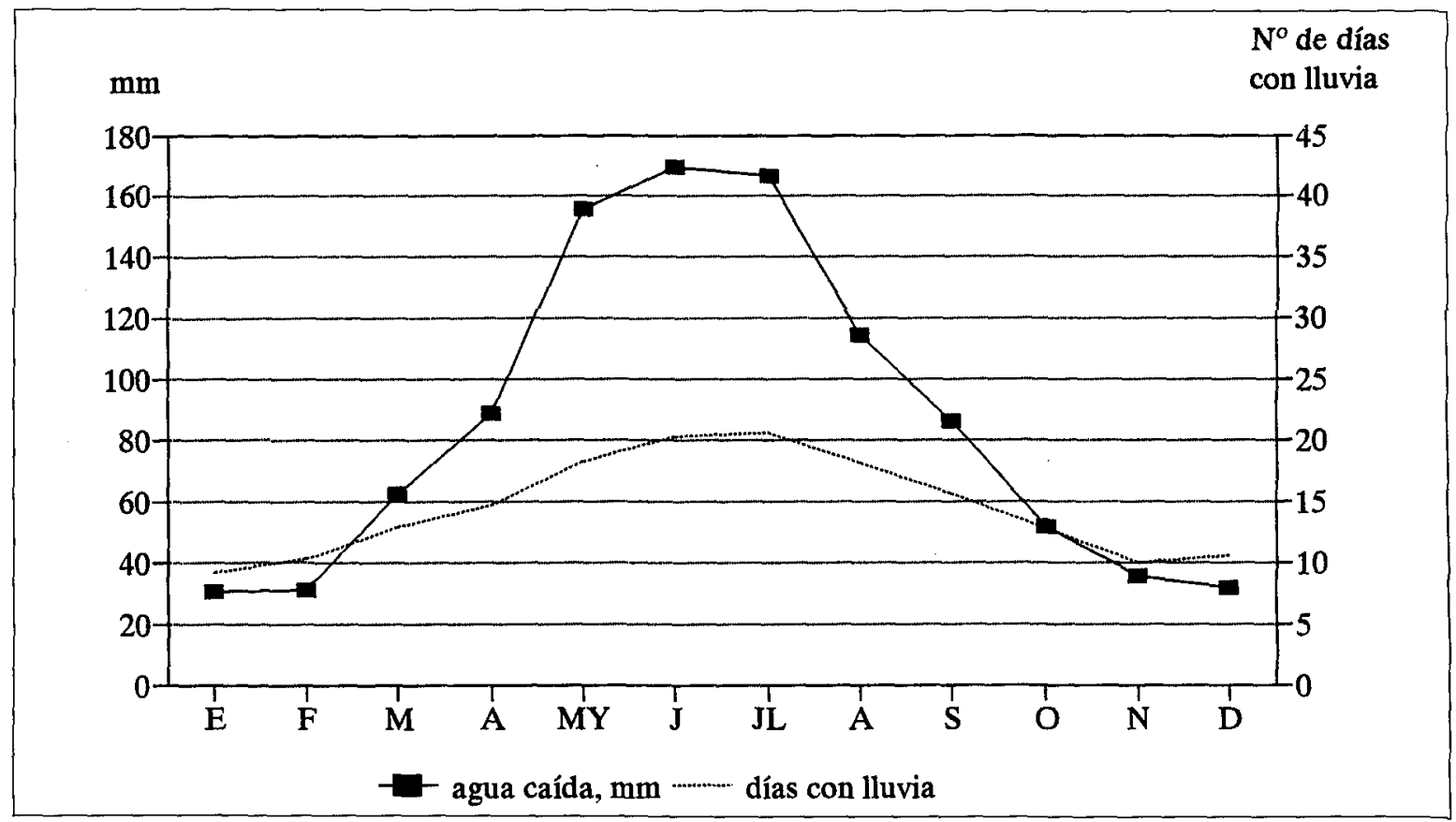

Figura 6: Distribución media mensual de la precipitación y el número de días con lluvia en Babía Cumberland (1960-1994).

No sería erróneo decir que tan sólo existen dos estaciones, con marcadas diferencias: el invierno, lluvioso, que se adelanta a mayo; y el verano, seco, que se adelanta a noviembre. Los cuatro meses restantes representan la transición de una a otra estación del año.

\section{2) La intensidad de la lluvia.}

El análisis de la intensidad que presenta la lluvia en Bahía Cumberland se ha realizado utilizando la serie de 1961 a 1994, por ser el único período que disponía de registros cada 12 horas. Para ello, se ha recopilado el número de veces que ha llovido en 12 horas según los siguientes intervalos: inferior a $1.0 \mathrm{~mm}$; de 1.0 a $9.9 \mathrm{~mm}$; entre 10.0 y $19.9 \mathrm{~mm}$; de 20.0 a $29.9 \mathrm{~mm}$; de 30.0 a $39.9 \mathrm{~mm}$; de 40.0 a $49.9 \mathrm{~mm}$; e igual o superior a $50.0 \mathrm{~mm}$.

Se ha contabilizado un total de 8.341 episodios con precipitación ${ }^{5}$, concentrándose casi la mitad de ellos, el $48 \%$, entre los meses de mayo y agosto, 4.024 eventos con lluvia.

$\mathrm{La}$ intensidad en 12 horas más frecuente es la comprendida entre $1.0 \mathrm{~mm}$ y $9.9 \mathrm{~mm}$, ya que más de la mitad de los episodios contabilizados, el 58.3\% (4.860

5. Se entiende por episodio o evento con precipitación aquel que en el transcurso de 12 horas ha registrado una lluvia superior a $0.1 \mathrm{~mm}$. 
CARACTERIZACIÓN DE LA PLUVIOSIDAD DE BAHÍA CUMBERLAND (ISLA DE ROBINSON CRUSOE) CEIILE

CUADRO III

LA FRECUENCIA DE LOS EPISODIOS LLUVIOSOS EN 12 HORAS DE DIFERENTES INTENSIDADES EN BAHİA CUMBERIAND (1960-1994)

\begin{tabular}{|c|r|r|r|r|r|r|r|r|r|r|r|r|r|}
\hline Intensidad/mm & \multicolumn{1}{|c|}{ E } & \multicolumn{1}{|c|}{ F } & M & A & M & J & JL & A & S & O & N & D & TOTAL \\
\hline < a 1.0 & 174 & 194 & 210 & 238 & 245 & 229 & 247 & 243 & 248 & 200 & 191 & 188 & 2.607 \\
1.0 a 9.9 & 211 & 234 & 295 & 369 & 550 & 716 & 683 & 559 & 452 & 347 & 227 & 217 & 4.860 \\
10.0 a 19.9 & 17 & 20 & 36 & 38 & 89 & 87 & 121 & 69 & 46 & 28 & 17 & 18 & 586 \\
20.0 a 29.9 & 2 & 1 & 12 & 16 & 30 & 32 & 25 & 22 & 15 & 5 & 5 & 4 & 169 \\
30.0 a 39.9 & 0 & 0 & 4 & 7 & 16 & 14 & 10 & 8 & 6 & 2 & 2 & 3 & 72 \\
40.0 a 49.9 & 1 & 1 & 0 & 3 & 3 & 9 & 2 & 2 & 1 & 2 & 0 & 0 & 24 \\
$>$ a 50.0 & 1 & 0 & 3 & 4 & 6 & 4 & 2 & 1 & 1 & 0 & 1 & 0 & 23 \\
\hline TOTAL & 406 & 450 & $\mathbf{5 6 0}$ & $\mathbf{6 7 5}$ & $\mathbf{9 3 9}$ & $\mathbf{1 . 0 9 1}$ & $\mathbf{1 . 0 9 0}$ & $\mathbf{9 0 4}$ & $\mathbf{7 6 9}$ & $\mathbf{5 8 4}$ & $\mathbf{4 4 3}$ & $\mathbf{4 3 0}$ & $\mathbf{8 . 3 4 1}$ \\
\hline
\end{tabular}

de un total de 8.341), se hallan en este intervalo. Le siguen en importancia las lloviznas o "garúas" con una intensidad inferior a $1.0 \mathrm{~mm} / 12 \mathrm{~h}$, que suponen el $31.2 \%$ del total. Los dos intervalos que incluyen las mayores intensidades tan sólo representan el $0.3 \%$, cada uno de ellos.

En la distribución mensual, siempre son los meses invernales los que detentan el mayor número de episodios lluviosos, independientemente de su intensidad. Se observa que las lloviznas más débiles se reparten casi por igual a lo largo de todo el año, entre el $6.7 \%$ en enero y el $9.5 \%$ en agosto y septiembre. Este hecho se explicaría por el efecto que el relieve ejerce en el estancamiento y desarrollo de la nubosidad en las partes altas de los cordones montañosos. A consecuencia de ello es muy frecuente la presencia de niebla a partir de cierta altitud y llovizna en las partes más bajas (CERECEDA et al., 1994). En cambio, conforme aumenta la intensidad de los eventos lluviosos éstas tienden a concentrarse, cada vez más, en los meses del otoño e invierno. Es el caso de las comprendidas entre 40.0 y $49.9 \mathrm{~mm} / 12 \mathrm{~h}$ con el $37.5 \%$ de las mismas en junio, o las de más de 50.0 $\mathrm{mm} / 12 \mathrm{~h}$ cuyo máximo anual lo ostenta mayo, con el $26.1 \%$ de los casos. Al analizar estos intervalos hay que tener en cuenta que aunque el número de episodios es muy bajo su importancia estadística resulta considerable.

Al estudiar el papel de las intensidades de la lluvia en cada uno de los meses, se apuntan algunos matices estacionales diferenciadores en el caso de los intervalos más débiles. Así, en noviembre, diciembre, enero y febrero (verano) las lluvias entre 1.0 y $9.9 \mathrm{~mm} / 12 \mathrm{~h}$ son las más frecuentes y suponen el $52 \%$ del total mensual, seguido de las de menos de $1.0 \mathrm{~mm} / 12 \mathrm{~h}$ con el $43 \%$; en cambio, en junio, julio y agosto (invierno) el primer intervalo de intensidad (inferior a 1.0 $\mathrm{mm} / 12 \mathrm{~h}$ ) pierde importancia en favor del segundo (de 1.0 a $9.9 \mathrm{~mm} / 12 \mathrm{~h}$ ), con el $23.5 \%$ y el $63 \%$ respectivamente. 

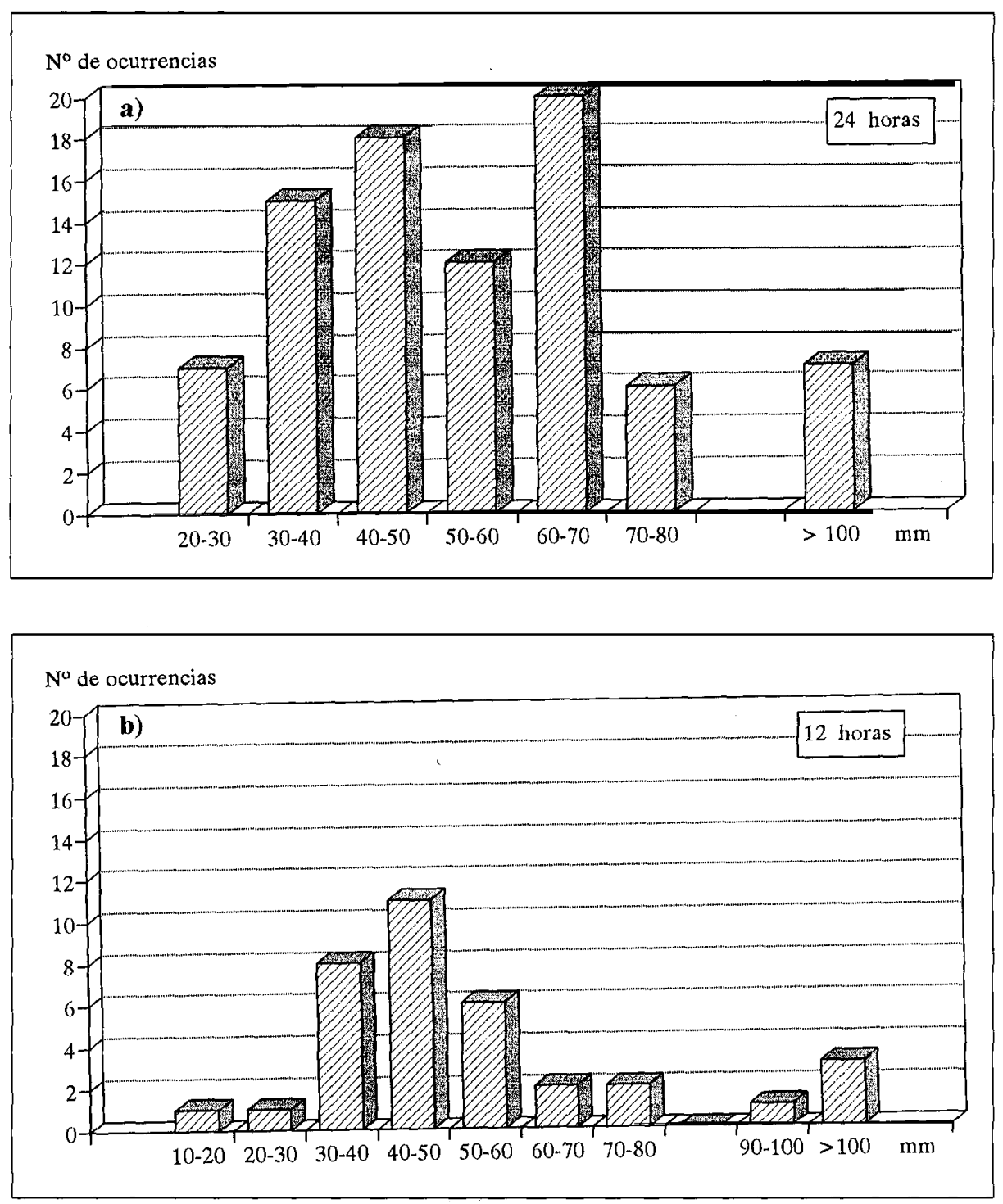

Figura 7a,b: Frecuencias absolutas de la máxima precipitación en 24 boras (1902-1994) y en 12 boras (1961-1994).

En los últimos 89 años se han superado los 100.0 milímetros/día en siete ocasiones, y en tres de ellas la lluvia cayó en tan sólo 12 horas ${ }^{6}$ (Fig. 7a,b). En el caso de la máxima intensidad en 24 horas, las frecuencias absolutas indican que es el intervalo de 60 a $70 \mathrm{~mm}$ el más común, con el $23.8 \%$ de los casos, seguido por el grupo de 40 a $50 \mathrm{~mm}$, con el $21.5 \%$. Si se considera el período de 12 horas, las lluvias más frecuentes son las comprendidas entre 40 y $50 \mathrm{~mm}$, con el $32.5 \%$ de las ocasiones en los ultimos 34 años.

6. No se puede conocer intensidades inferiores a 24 horas en fechas anteriores a 1961. 
La intensidad más elevada conocida en Bahía Cumberland, en este siglo, es la ocurrida entre las 8 de la mañana del día 12 de mayo de 1980 y las 8 horas del día siguiente, en la que se contabilizaron $290.3 \mathrm{~mm}$, de los cuales 265.0 $\mathrm{mm}$ cayeron en las últimas 12 horas. Esa noche se produjo un gran aluvión que anegó todo el poblado de San Juan Bautista con el material arrastrado torrencialmente por las quebradas, causando enormes pérdidas económicas en las viviendas de San Juan Bautista si bien no hubo personas muertas. Un segundo aluvionamiento, que afectó sobre todo al sector oriental de Bahía Cumberland, se produjo después de llover $106.4 \mathrm{~mm}$ entre las 8 y 19 horas del día 6 de marzo de 1972, habiendo caído $54.2 \mathrm{~mm}$ en las 12 horas del día anterior.

\section{CUADRO IV}

LAS MAYORES INTENSIDADES DE LA LLUVIA EN

24 Y 12 HORAS (BAHÍA CUMBERLAND, 1902-1994)

\begin{tabular}{|rr|rr|}
\hline \multicolumn{2}{|c|}{ En 24 horas } & \multicolumn{2}{|c|}{ En 12 horas } \\
\hline \multicolumn{1}{|c|}{ mm } & Fechas & mm & \multicolumn{1}{c|}{ Fechas } \\
\hline 105.9 & 24 junio 1922 & 106.4 & 6 marzo 1972 \\
81.2 & 7 julio 1928 & 108.1 & 11 al 12 marzo 1972 \\
84.0 & $i$ ? julio 1931 & 265.0 & 12 mayo 1980 \\
108.7 & 29 mayo 1945 & 91.7 & 3 julio 1984 \\
86.0 & 2 marzo1967 & & \\
109.1 & 6 marzo1972 & & \\
108.1 & 11 junio 1972 & & \\
290.3 & 12 mayo 1980 & & \\
107.1 & 3 julio 1984 & & \\
125.6 & 19 marzo1986 & & \\
83.9 & 27 julio 1988 & & \\
85.0 & 31 enero1992 & & \\
\hline
\end{tabular}

Se sabe que en esta localidad, durante el último siglo, se ha superado el umbral de $100 \mathrm{~mm}$ en 24 horas en cinco ocasiones más y, sin embargo, la población isleña no recuerda consecuencias catastróficas, con arrastres de materiales y troncos de los árboles, como en las otras dos fechas. Cabe suponer que la explicación de este hecho sea que en los dos eventos lluviosos causantes de los aluviones la intensidad fuera superior y que gran parte de la lluvia cayera en menos de 12 horas. Desgraciadamente, no existe la posibilidad de corroborar esta afirmación por la ausencia de pluviógrafo en esas fechas y por efectuarse los registros pluviométricos tan sólo cada $12 \mathrm{~h}$.

Según la fórmula de Gumbel (MARZOL, 1988a), a través de la cual se puede prever la cantidad máxima de lluvia que va a caer en 24 y 12 horas según los diferentes períodos de recurrencia, hay que indicar que en Bahía Cumberland 
sería normal que cada 10 años se produjera una intensidad de lluvia diaria de $110 \mathrm{~mm}$ o una de $118 \mathrm{~mm}$ en doce horas (Fig. 8).

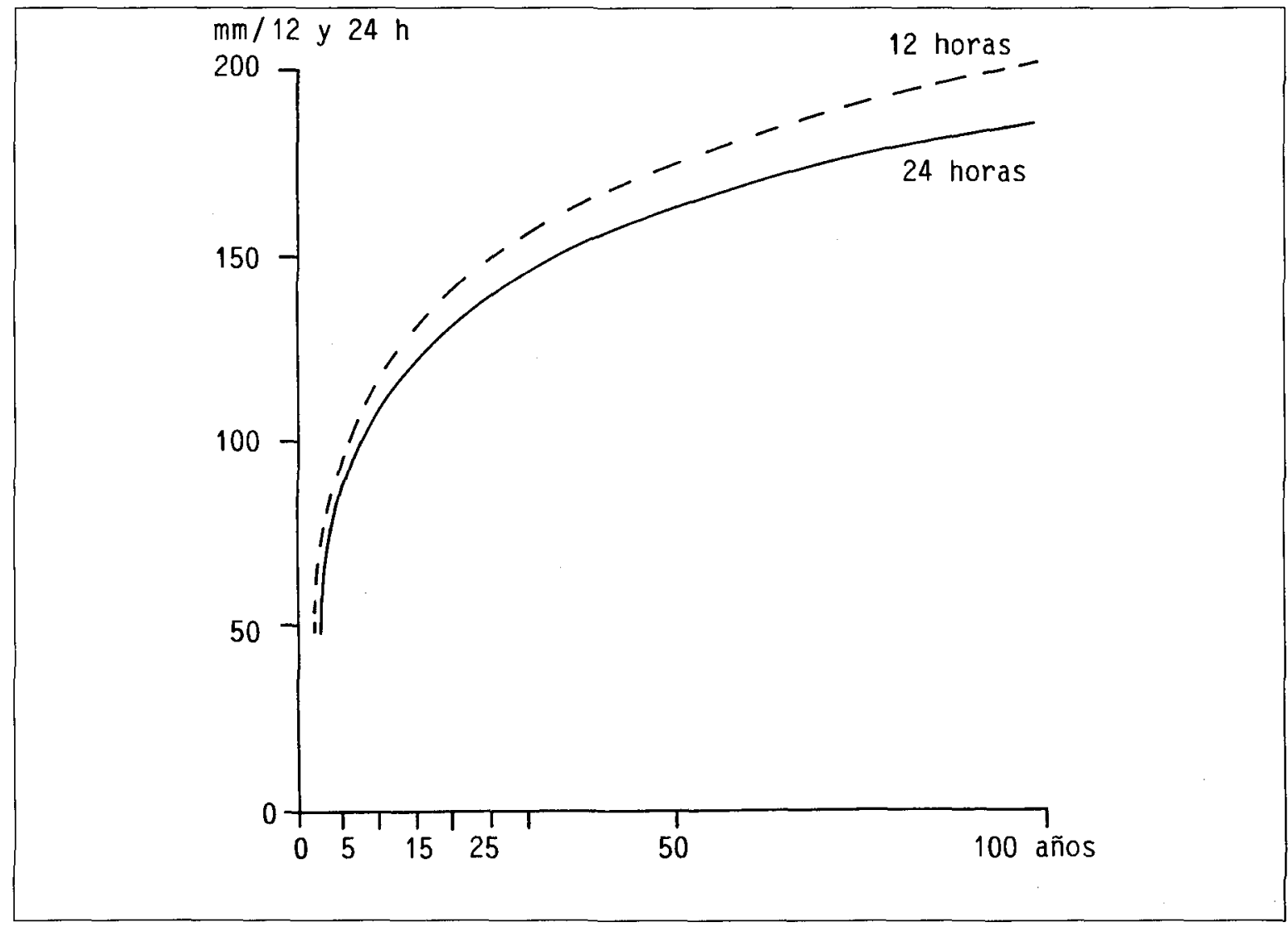

Figura 8. Cantidades máximas de precipitación que se pueden estimar en 24 y 12 boras en Babía Cumberland según la fórmula de Gumbel.

3) La situación atmosférica cuando se producen las lluvias más intensas en Babia Cumberland.

La sinópsis del estado de la atmósfera cuando se registran cuantiosas precipitaciones en el archipiélago de Juan Fernández, es similar a la situación de las islas Canarias en el hemisferio Norte (MARZOL, 1988b). En Robinson Crusoe se siguen las pautas lógicas de la circulación atmosférica en el Pacífico suroriental ante situaciones de fuerte inestabilidad. En estos casos, el Anticiclón del Pacífico Sur se retira hacia el Norte de su posición habitual, hasta los $20^{\circ}$ Sur, y mantiene una presión en su núcleo de $1025 \mathrm{hPa}$. Esta retirada es aprovechada por las perturbaciones templadas, asociadas al Frente Polar y ligadas a la corriente en chorro del Hemisferio Sur, que se aproximan al continente sudamericano siguiendo un eje SW-NE, entre los $60^{\circ}$ y $30^{\circ} \mathrm{S}$ y los $1401-751$ Oeste, y alcanzan la costa de Chile con una presión próxima a los $1000 \mathrm{hPa}$. 
Del análisis de las cartas sinópticas se puede extraer que los frentes perturbados, en su trayectoria, barren la isla Robinson Crusoe con una componente oeste. Su posterior debilitamiento, entre el archipiélago y el continente, se explica por el papel que juega la corriente oceánica de Humboldt, que enfría por la base a la masa de aire y la estabiliza; en segundo lugar, porque al entrar en contacto con el continente las depresiones dejan de disponer la fuente de retroalimentación oceánica; y, sobre todo, porque las células anticiclónicas aprisionan a las depresiones contra el continente, debilitándolas y haciendo disminuir su velocidad.

Los mapas superficiales de los días 6 de marzo de 1972, 4 de julio de 1984, 19 de abril de 1986 y 13 de mayo de 1980 reúnen todas estas condiciones. Sólo en la del 6 de marzo, el Anticiclón del Pacífico Sur se encuentra en una posición más meridional, a $30^{\circ}-35^{\circ}$ de latitud, por ser verano, y la depresión que se situaba sobre Juan Fernández tampoco era tan profunda puesto que tenía $1018 \mathrm{hPa}$ en su núcleo (Fig.9).

El mapa del 13 de mayo de 1980 sí posee la situación sinóptica superficial comentada anteriormente pero, en esta ocasión, la presión de la borrasca, situada a los $40^{\circ} \mathrm{S}$ y $85^{\circ} \mathrm{W}$, había llegado a ser de tan sólo $975 \mathrm{hPa}$ el día anterior. Del
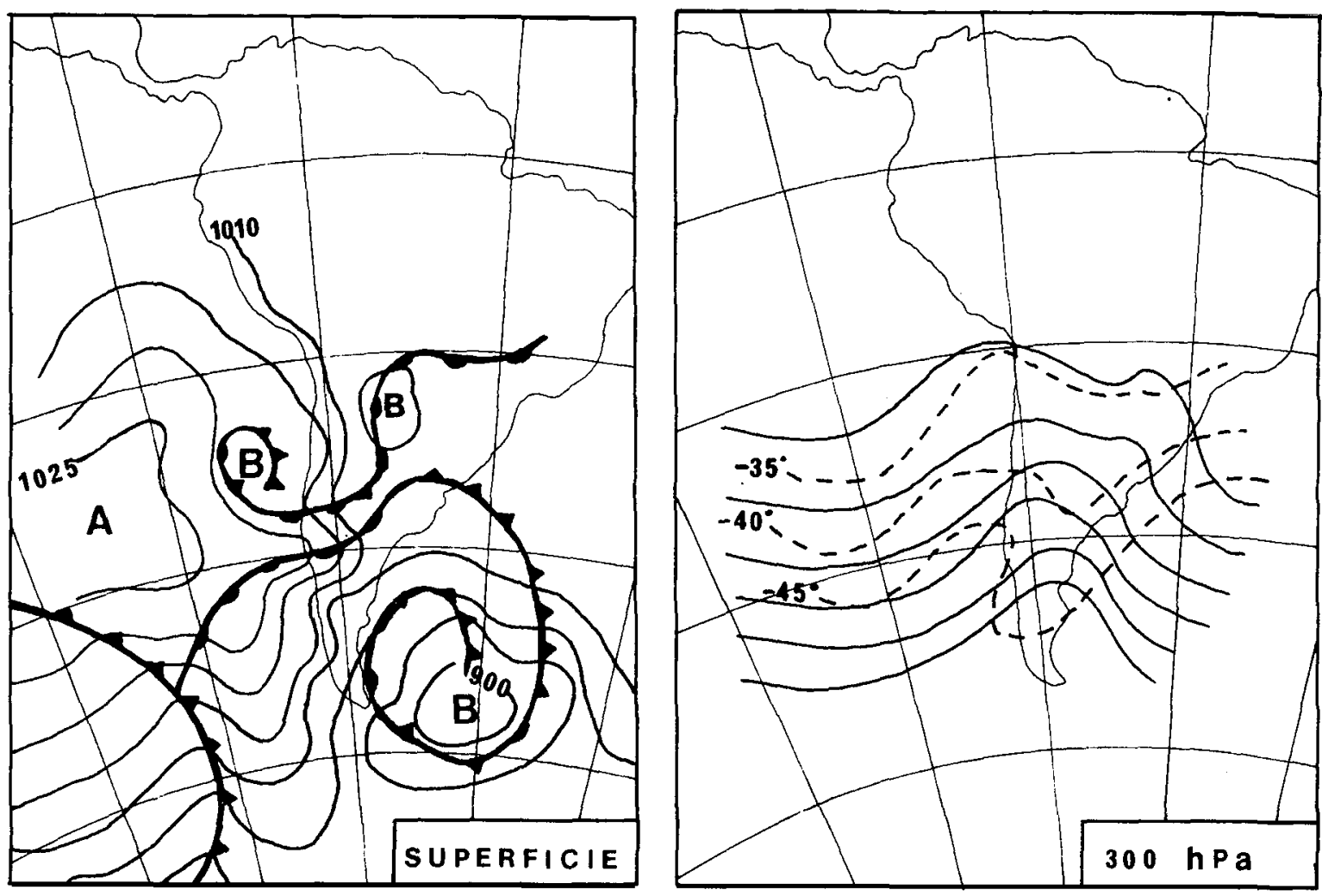

Figura 9. Cartas de superficie y de 300 bPa del día 6 de marzo de 1972, a las $00.00 \mathrm{~b}$ $T M G$. 
día 11 al 13 de este mes se observa nítidamente como las dos células anticiclónicas, en las que se suele dividir el Anticiclón del Pacífico Sur, aprisionaban a la borrasca frente a las costas de Valparaiso (Fig. 10).
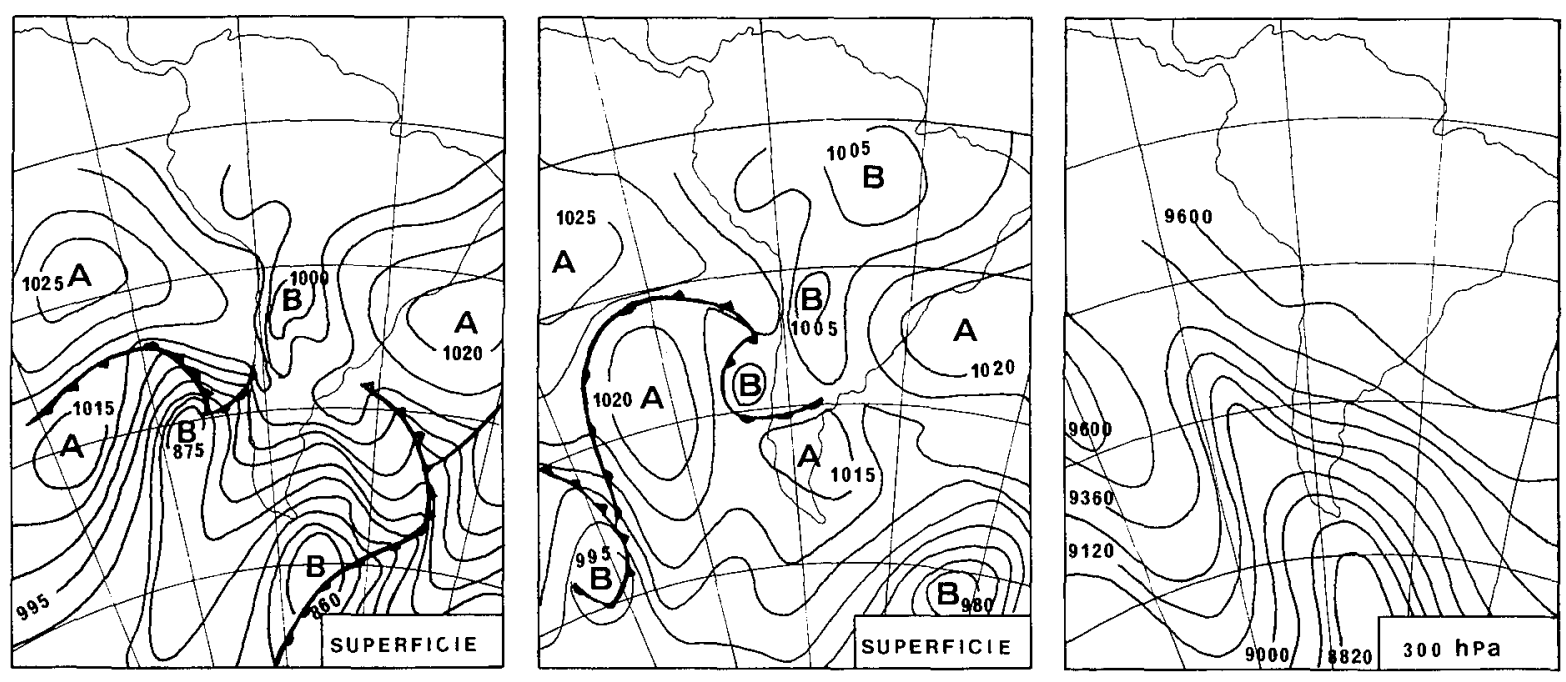

Figura 10. Cartas de superficie de los días 11 y 13 de mayo de 1980 y carta de 300 bPa del 13 de mayo de 1980.

En todas las topografias de 300 y $250 \mathrm{hPa}$ consultadas, la circulación era zonal, con temperaturas entre 40 y $45^{\circ} \mathrm{C}$ negativos, y en ocasiones mostraba la existencia de fuertes vientos. Tan sólo en el episodio lluvioso de mayo de 1980 existía una profunda vaguada desde el Sur y que discurría paralela a la costa chilena, teniendo su eje en el meridiano $85 \mathrm{~W}$.

\section{Conclusiones}

De todos los rasgos climáticos que presenta la isla Robinson Crusoe, el que más destaca es la lluvia. Así lo demuestra el análisis de la información de la estación meteorológica situada en Bahía Cumberland.

El carácter ciclónico de las precipitaciones que se registran en esta isla condiciona su estacionalidad, claramente concentradas en los meses invernales (el $76 \%$ del monto total), y está supeditado al paso de las familias de borrascas del Frente Polar. Cuando esto ocurre, la proximidad del archipiélago al núcleo de las bajas presiones y la potencia de las mismas van a determinar el volumen de la lluvia y su intensidad. Estas condiciones se reconocieron en el análisis de los registros meteorológicos y en las cartas sinópticas de los eventos más lluviosos. En el caso del 13 de mayo de 1980, además, se constató la presencia de una profunda vaguada en la topografia de $300 \mathrm{hPa}$.

Además de intensificar las precipitaciones y distribuirlas desigualmente en la isla, el papel del relieve es fundamental en la generación de lloviznas, las que se manifiestan en forma homogénea a lo largo de todo el año. Estas suponen un 
escaso volumen de agua colectada pero implican a más de un cuarto de los días lluviosos que se producen en Bahía Cumberland.

Conocer la dinámica de las precipitaciones es vital en esta isla debido al equilibrio inestable en que se encuentran sus ecosistemas, al aporte que el agua da a las diferentes formaciones vegetacionales y, lo más importante, a los riesgos de aluviones a que están sujetos los pobladores de San Juan Bautista. Desde estos puntos de vista, merece destacar que la pluviosidad más frecuente tiene una intensidad media o moderada, y supone un importante aporte de agua al suelo pero también un riesgo de pérdida del mismo.

Con respecto al riesgo de aluviones, es necesario hacer estudios más afinados sobre la la intensidad de la lluvia y el volumen de la misma puesto que se puede esperar un episodio de más de $100 \mathrm{~mm}$ en 24 horas una vez cada 10 años

\section{Agradecimientos}

Agradecemos a la Dirección Meteorológica de Chile por la información de la estación de Juan Fernández, en especial la colaboración prestada por el Sr. Subdirector D. Héctor Muñoz, D. Jorge Pérez, D. Juan Vera y Doña M. ${ }^{a}$ Angélica Sanhueza, y a D. Mauricio Calderón, de CONAF (Corporación Nacional Forestal).

Investigación realizada gracias a la subvención de la Dirección General de Universidades e Investigación del Gobierno de Canarias. España.

Proyecto FONDECYT, Chile n. ${ }^{\circ} 1940678$ y AES KM 175-2-9082B

ANEXO I

DATOS CLMÁTICOS DE BAHÍA CUMBERLAND

\begin{tabular}{|c|c|c|c|c|c|c|c|}
\hline & \multicolumn{2}{|c|}{ TEMPERATURAS } & \multirow{2}{*}{$\begin{array}{r}\text { HUMEDAD } \\
\text { MEDIA \% }\end{array}$} & \multirow{2}{*}{$\begin{array}{l}\text { PRESION } \\
\text { MEDIA hPa }\end{array}$} & \multicolumn{2}{|c|}{ PRECIPITACION MEDIA } & \multirow{2}{*}{$\begin{array}{l}\text { DLAS DE } \\
\text { LLUVIA }\end{array}$} \\
\hline & $\begin{array}{l}\text { T. Máx. } \\
{ }^{\circ} \mathrm{C}\end{array}$ & $\begin{array}{l}\text { T. Min. } \\
{ }^{\circ} \mathrm{C}\end{array}$ & & & $\begin{array}{c}1902 \cdot 1994 \\
\mathrm{~mm}\end{array}$ & $\begin{array}{c}1960-1994 \\
\mathrm{~mm}\end{array}$ & \\
\hline $\mathrm{E}$ & 27.5 & 10.6 & 72 & 1019.2 & 27.5 & 30.4 & 9 \\
\hline $\mathrm{F}$ & 27.3 & 10.4 & 72 & 1018.8 & 31.0 & 30.8 & 10 \\
\hline M & 27.0 & 9.0 & 73 & 1019.3 & 50.8 & 62.6 & 13 \\
\hline A & 24.7 & 8.2 & 76 & 1019.4 & 84.2 & 88.7 & 15 \\
\hline $\mathbf{M}$ & 23.2 & 6.3 & 78 & 1017.8 & 149.2 & 155.5 & 18 \\
\hline $\mathrm{J}$ & 22.2 & 5.3 & 78 & 1019.2 & 165.9 & 169.7 & 20 \\
\hline $\mathrm{J}$ & 19.4 & 5.0 & 78 & 1019.4 & 164.8 & 166.7 & 21 \\
\hline$A$ & 21.1 & 3.0 & 76 & 1021.9 & 112.0 & 114.6 & 18 \\
\hline S & 21.8 & 5.0 & 74 & 1022.0 & 79.9 & 85.9 & 16 \\
\hline $\mathrm{O}$ & 21.6 & 6.2 & 72 & 1021.9 & 53.3 & 51.5 & 13 \\
\hline $\mathbf{N}$ & 23.9 & 7.6 & 72 & 1020.9 & 35.4 & 35.5 & 10 \\
\hline $\mathrm{D}$ & 28.9 & 9.2 & 71 & 1020.1 & 28.8 & 31.7 & 11 \\
\hline AÑO & 28.9 & 3.0 & 74 & 1020.0 & 982.8 & 1023.7 & 174 \\
\hline
\end{tabular}

T. Max.: temperatura máxima absoluta (1902-1994).

T. min.: temperatura mínima absoluta (1902-1994).

H\%: humedad relativa media obtenida de las 8, 14 y 20 horas (1960-1979,1985,1988,1990-1991).

Presión media: presión al nivel del mar (1968-1991, excepto los años 1983-1984,1986-1987).

Días de lluvia (1960-1994). 


\section{Referencias bibliogräficas}

CASTRO, C.; CERECEDA, P.; CALDERÓN, M. \& SCHEMENAUER, R.S. ,1995. Aplicación de SIG para un plan de manejo de la isla Robinson Crusoe, Chile. Enviado a la Revista Insula.

CAVIEDES, S., 1971. Perturbations during the predominance antyciclonic summer weather in Central Chile. Revista Geográfica, IPGH (74): 71-81.

CERECEDA, P.; SCHEMENAUER, R.S \& ZUNINO, H., 1994. Distribución de la precipitación en la isla de Robinson Crusoe. Revista de Geografía Norte Grande, 21: 33-36.

MARZOL, M.V., 1988a. La lluvia: un recurso natural para Canarias. Caja General de Ahorros de Canarias. Santa Cruz de Tenerife.

MARZOL, M.V., 1988b. Situaciones atmosféricas de lluvias intensas en Canarias. En Avenidas fluviales e inundaciones en la cuenca del Mediterráneo. CECOURS, Viena (UNESCO)-Universidad de Alicante, 107-116.

O.M.M.- Naciones Unidas - Gobierno de Chile, 1964. Proyecto Hidrometeorológico. Climatología de Chile (1916-1945). Fasc. 1.

PEÑA, O. \& H. ROMERO, 1976. Rutas ciclonales en el Pacífico Sur: situaciones de primavera y verano". Revista Pacífico Sur, 5: 113-127. Comisión permanente del Pacífico Sur.

ZUNINO, H., 1993. Variabilidad espacial de las precipitaciones y potencial hidrológico de la niebla en la isla de Robinson Crusoe, archipiélago de Juan Fernández, Chile. Memoria para optar al título de geógrafo, Pontificia Universidad Católica de Chile. 